\title{
Larviciding Activity of Acroptilon repens Extract against Anopheles stephensi, Culex pipiens and Culex quinquefaciatus under Laboratory Conditions
}

\author{
Ramesh Toolabi ${ }^{1}$, Mohammad Reza Abai ${ }^{1 *}$, Mohammad Mehdi Sedaghat ${ }^{1}$, Hassan Vatandoost ${ }^{1}$, \\ Mansooreh Shayeghi' ${ }^{1}$, Saeed Tavakoli' ${ }^{2}$, Mohammad Sistanizadeh Aghdam ${ }^{1}$
}

\section{Ramesh Toolabi', Mohammad Reza Abai ${ }^{1 *}$, Mohammad Mehdi Sedaghat ${ }^{1}$, Hassan Vatandoost ${ }^{1}$, Mansooreh Shayeghi ${ }^{1}$, Saeed Tavakoli ${ }^{2}$, Mohammad Sistanizadeh Aghdam}

'Department of Medical Entomology and Vector Control, School of Public Health, Tehran University of Medical Sciences, Tehran, IRAN. 2Department of Pharmacognosy, Faculty of Pharmacy, Tehran University of Medical Sciences, Tehran, IRAN.

Correspondence

\section{Dr. Mohammad Reza Abai}

Qods Ave, Poursina Ave, Department. of Medical Entomology and Vector Control, School of Public Health, Tehran University of Medical Sciences, Tehran 1417613151, IRAN.

Phone no: 00982142933112

Fax: 00982188951393

E-mail: abaimr@tums.ac.ir

\section{History}

- Submission Date: 17-09-2017

- Review completed: 20-11-2017;

- Accepted Date: 19-12-2017

DOI : 10.5530/pj.2018.3.74

Article Available online http://www.phcogj.com/v10/i3

\section{Copyright}

(c) 2018 Phcog.Net. This is an openaccess article distributed under the terms of the Creative Commons Attribution 4.0 International license.

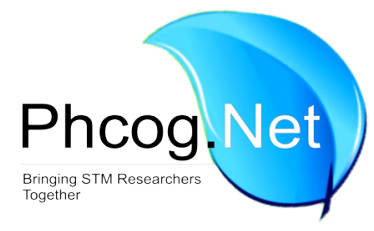

\begin{abstract}
Introduction: Due to the emergence of insecticide resistance among the vectors of human diseases, there is a need to explore the use of plant extracts which are safe alternatives to conventional chemical larvicides used in control of vector-borne diseases. The aim of this study was to evaluate the larvicidal activity of Acroptilon repens against third instar larvae of Anopheles stephensi, Culex pipiens and Culex quinquefaciatus. Materials and Methods: The aerial parts of $A$. repens plants was dried in the shaded places for 3 days at $26-28^{\circ} \mathrm{C}$. The leaves, flowers and stems were blended to crashed form using an electric blender. The larvicidal activity of total extract of $A$. repens were evaluated against third instar larvae stage of mosquito vectors, An. stephensi, $C x$. pipiens and $C x$. quinquefaciatus under laboratory conditions with $24 \mathrm{~h}$ exposure period. Data were subjected to probit regression analysis in order to estimate the lethal concentrations for $50 \%$ and $90 \%$ mortality values. Result: The extract of $A$. repens exhibited significant larvicidal activity against third instar larvae of $A n$. stephensi, with $24 \mathrm{~h} \mathrm{LC}$ of 0.2970 and $\mathrm{LC}_{90}$ of $2.2097 \mathrm{mg} / \mathrm{l}$. The $\mathrm{LC}_{5}$ and $\mathrm{LC}_{90}$ values were 2.5047 and $24.7374 \mathrm{mg} / \mathrm{l}$ for CX. pipiens and 2.9047 and $16.1459 \mathrm{mg} / \mathrm{l}$ for CX. quinquefaciatus. Conclusion: The extract of $A$. repens can serve as a natural larvicide against $A n$. stephensi, $C x$. pipiens and $C x$.quinquefaciatus. According to the larvicidal properties of this plant, formulating an extract of $A$. repens which is known as an abundant agricultural weed in Iran creates an alternative to chemical larvicides and providing a job opportunities.

Key words: Acroptilon repens, Anopheles stephensi, Culex pipiens, Cx. quinquefaciatus, Larvicidal activity, Total extract.
\end{abstract}

\section{INTRODUCTION}

Vector-borne diseases are illnesses transmitted by the vectors which can transmit infectious diseases between humans or from animals to humans and account more than $17 \%$ of all infectious diseases, causing more than 1 million deaths annually. One sixth of the illness and disability suffered worldwide is due to vector-borne diseases. ${ }^{1}$ Dengue is an acute mosquito-borne viral infection which regarded as the most important arboviral disease and more than 2.5 billion people in over 100 countries live in areas where has a significant socioeconomic and disease burden. ${ }^{2}$ Malaria causes were more than 214 million in 2015 which most of them children under 5 years of age in the world. ${ }^{3}$ Anopheles stephensi is considered as both urban and rural mosquito in Iran. ${ }^{4}$

Bio pesticides have been found to contain natural constituents of plants, animals, bacteria, viruses and fungi that have been proposed as an alternative to chemical pesticides for insect control. These materials are harmless to humans, animals and the environment and are easily decomposed in soil and are not stored in plants or animals. ${ }^{5}$ Over the past two decades, numerous extracts or essential oils from indigenous plants have been evaluated against larvae of $A n$. stephensi. ${ }^{6}$ Many of vector borne diseases are preventable through informed protective measures. Although there are several methods for controlling the Anopheles mosquitoes, however the environmental effects and resistance are the main human concern. Synthetic pyrethroids which considered as the most effective insecticides against anophelines, are still expensive and beyond the financial resources of some countries. ${ }^{7}$ Members of the plant families including Solanaceae, Asteraceae, Cladophoraceae, Labiatae, Miliaceae, Oocystaceae and Rutaceae have various types of larval, adulticidal or repellent activities against different species of mosquitoes. ${ }^{8}$ This study aimed to study the larviciding activity of total extract of $A$.
Cite this article: Toolabi R, Abai MR, Sedaghat MM, Vatandoost H, Shayeghi M, Tavakoli S, et al. Larviciding Activity of Acroptilon repens Extract against Anopheles stephensi, Culex pipiens and Culex quinquefaciatus Under Laboratory Conditions. Pharmacog J. 2018;10(3):453-56. 
repens which considered as a dominant and disturbing weeds in the garden and agricultrural lands.

\section{MATERIALS AND METHODS}

\section{Mosquito rearing}

The rearing and maintenance of An. stephensi, Cx. pipiens and Cx. quinquefaciatus were conducted in the Culicidae Insectary of School of Public Health, Tehran University of Medical Sciences. Each species was reared in a separate room. The larvae and adult rearing rooms were equipped with the electronic devices for adjusting temperature, light and humidity. The insectary conditions were fixed at $29 \pm 2{ }^{\circ} \mathrm{C}$, dark to light photoperiod of $16: 8 \mathrm{~h}$ and relative humidity of $70 \pm 10 \%$. The late $3 \mathrm{rd}$ instar larvae were used for evaluation of larvicidal effects of total extract. Plastic containers with dimension of $35 \times 25 \mathrm{~cm}$ was used to rear the immature stages (eggs, larvae and pupae) of the mosquitoes. Two liters of de-chlorinated water with temperature of $24-25^{\circ} \mathrm{C}$ were used for immature rearing. Deposited eggs were gently released in the middle of teared paper to prevent the desiccation of mosquito eggs due to attachment to the margin of the containers. The temperature of the immature rooms was adjusted between 29 to $30^{\circ} \mathrm{C}$. In these conditions, the eggs were hatched after 1-2 days. Larvae were fed with flaky fish food which was added daily on the surface of the rearing water. Containers for immature stages were thoroughly washed with water and dishwashing liquid, well rinsed and then dried.

\section{MATERIALS}

Russian Knapweed, A. repens was collected at the flowering stage (Aug-Sep 2015) from natural habitats in the Maku district, West Azarbaijan province, Iran. A voucher specimen was deposited under code 2731UT in the herbarium of Department of Medical Entomology and Vector Control. The collected samples were allowed to dry in a shaded room and maintained inside a dark plastic bag.

\section{Extraction}

About $250 \mathrm{~g}$ crashed plant was transferred into the Buchner funnel of the percolator device. One thousand five hundred mills (1.5L) of pure methanol solvent (99.9\%) was added into the Buchner funnel so that the solvent height was about $5 \mathrm{~cm}$ above the surface of crushed plant. After $48 \mathrm{~h}$, the methanol was drained and collected in the crystallizer. This operation was repeated 3 times to collect the entire extract. After smoothing, using a filter paper, the resulting solution containing methanolsoluble compounds was collected. Concentration was performed by rotary evaporator in vacuum $\left(60-100 \mathrm{rpm}\right.$ and $\left.50^{\circ} \mathrm{C}\right)$. After evaporation of the solvent, the condensate extract was transferred to the crystallizer and put on the hood for complete drying. The condensate extract was diluted using pure ethanol as a solvent and the exposure concentration was prepared for the bioassays.

\section{Bioassays and larval mortality}

The larvicidal activity of the total extract was assayed according to WHO guideline. ${ }^{9,10}$ Preliminary tests were carried out to establish concentrations from stock solutions of the total extract. The stock concentration was $5.0 \mathrm{~g}$ per $100 \mathrm{ml}$ of pure ethanol $(50000 \mathrm{ppm})$ and the first higher exposure concentration was $781.25 \mathrm{ppm}$ which serially diluted until the lowest concentration $3.05 \mathrm{ppm}$.

For each concentration, 25 larvae were used. Each test run consisted of $224 \mathrm{ml}$ water, $1 \mathrm{ml}$ of test sample of stock solution and 25 larvae in $25 \mathrm{ml}$ water; so that the final volume was $250 \mathrm{ml}$. In the control group, $1 \mathrm{ml}$ of pure methanol was added to $249 \mathrm{ml}$ of de-chlorinated water in the 400 $\mathrm{ml}$ glass beakers. Mortality was read after $24 \mathrm{~h}$ exposure period.

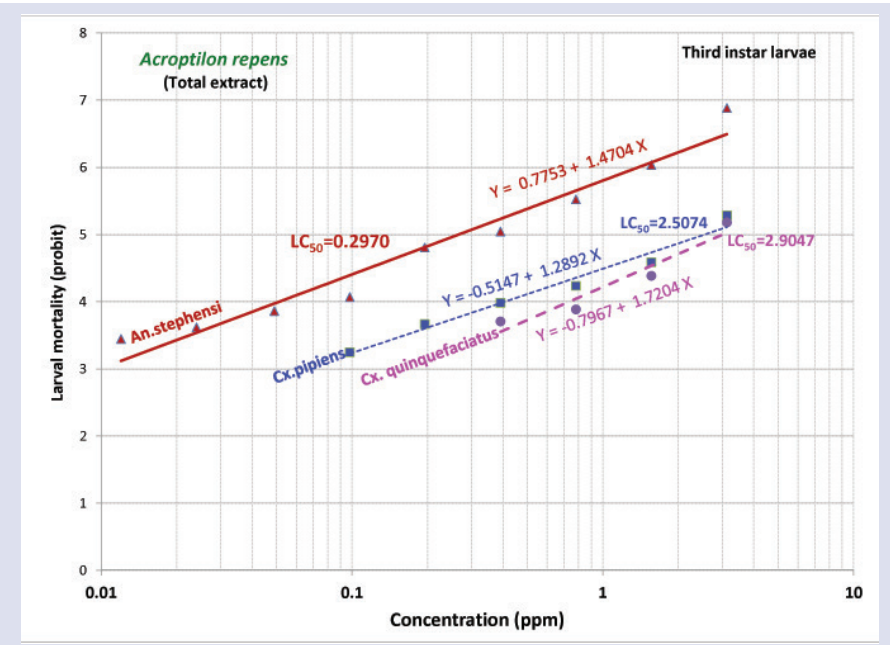

Figure 1: Comparative regression lines of total extract $A$. repens against third instar larvae of three species of mosquito vectors.

\section{Statistical analysis}

In the analysis, both dead and moribund larvae were considered as dead. The lethal concentrations $\left(\mathrm{LC}_{50}\right.$ and $\mathrm{LC}_{90}$ ) were calculated using probit regression analysis and related parameters determined. For all bioassays, the mortality rate was adjusted for the mortality in control group by using Abbott's correction (Abbot 1925) if the control mortality was between 5 and $20 \%$. Significant difference between the means of mortality rate for each mosquito species was assessed by ANOVA method using PASW release 18 .

\section{RESULTS}

The larvicidal activity of total extract $A$. repens was tested with 9 logarithmic concentrations from 3.05 to $781.25 \mathrm{ppm}$ with each concentration replicated at least 4 times. The lethal concentrations of $50 \%$ and $90 \%$ of the total extract of $A$. repens were estimated to be 0.2970 and $2.2097 \mathrm{ppm}$ for An. stephensi, 2.5074 and 24.7374 ppm for Cx. pipiens and 2.9047 and $16.1459 \mathrm{ppm}$ for $C x$. quinquefaciatus Table 1. The line equations of regression were estimated as $\mathrm{Y}=-0.7753+1.4704 \mathrm{X}, \mathrm{Y}=-0.5147+$ $1.2892 \mathrm{X}$ and $\mathrm{Y}=-0.7967+1.7204 \mathrm{X}$ respectively for An. stephensi, Cx. pipiens and $C x$. quinquefaciatus. The regression lines of total extract $A$. repens was compared between third instar larvae of three species of larvae (Figure 1).

\section{DISCUSSION}

Presently, sources for remedies and control of harmful insects are shifted to the natural resources and medicinal plants. So today, in addition to exploitation of natural habitats, extensive agricultural fields have been allocated for cultivation of medicinal plants, which are used for extraction and production of raw materials used in manufacturing of drugs and for various types of larvicides, insecticides and repellents. In this research, the larvicidal activity of total extract of $A$. repens was assessed and the value of $\mathrm{LC}_{50}$ and $\mathrm{LC}_{90}$ were found to be in the range of 0.3 to $3.0 \mathrm{ppm}$ and 2.2 to $24.7 \mathrm{ppm}$ respectively.

The only research on insecticidal properties of $A$. repens extract was carried out in China against some species of Lepidopteran larvae. Contact toxicity of $A$. repens fractions were assessed against the larvae of Mythimna separata, Plutella xylostella, Pieris rapae using immersion method. The results showed that the ethyl acetate fraction from the whole plant of $A$. repens at flowering stage had very strong contact toxicity against $5^{\text {th }}$ 
Table 1: Lethal concentrations ( $L C_{50}$ and $\mathrm{LC}_{90}$ ) and associated statistics $24 \mathrm{~h}$ bioassay tests of total extract $A$. repens against third instar larvae of three species of Culicidae mosquitoes

\begin{tabular}{|c|c|c|c|c|c|c|c|}
\hline Mosquito species & a & $b \pm S E$ & $\begin{array}{l}\mathrm{LC}_{50}(\mathrm{ppm}) \\
\pm 95 \% \mathrm{C} . \mathrm{L} .\end{array}$ & $\begin{array}{l}\mathrm{LC}_{90} \text { (ppm) } \\
\pm 95 \% \text { C.L. }\end{array}$ & $\begin{array}{c}\mathrm{X}^{2} \\
\text { (Heterogeneity) }\end{array}$ & $\begin{array}{c}X^{2} \\
\text { table (df) }\end{array}$ & p-Value \\
\hline \multirow[t]{3}{*}{ An. stephensi } & \multirow[t]{3}{*}{0.7753} & \multirow{3}{*}{$\begin{array}{c}1.4704 \pm \\
0.110\end{array}$} & 0.2317 & 1.5987 & \multirow[t]{3}{*}{$29.479^{*}$} & \multirow[t]{3}{*}{$18.475(7)$} & \multirow[t]{3}{*}{0.01} \\
\hline & & & 0.2970 & 2.2097 & & & \\
\hline & & & 0.3720 & 3.3948 & & & \\
\hline \multirow[t]{3}{*}{ Cx. pipiens } & \multirow[t]{3}{*}{-0.5147} & \multirow{3}{*}{$\begin{array}{c}1.2892 \pm \\
0.133\end{array}$} & 1.9163 & 13.5910 & \multirow[t]{3}{*}{$3.950^{* *}$} & \multirow[t]{3}{*}{$13.277(4)$} & \multirow[t]{3}{*}{0.01} \\
\hline & & & 2.5074 & 24.7374 & & & \\
\hline & & & 3.5957 & 60.0197 & & & \\
\hline \multirow[t]{3}{*}{ Cx. quinquefaciatus } & \multirow[t]{3}{*}{-0.7967} & \multirow{3}{*}{$\begin{array}{c}1.7204 \pm \\
0.187\end{array}$} & 2.3039 & 9.4268 & \multirow[t]{3}{*}{$4.528^{\star *}$} & \multirow[t]{3}{*}{$9.210(2)$} & \multirow[t]{3}{*}{0.01} \\
\hline & & & 2.9047 & 16.1459 & & & \\
\hline & & & 4.0888 & 39.7364 & & & \\
\hline
\end{tabular}

instar larvae of $M$. separate with corrected mortality of $80 \%$ even when the extract was diluted 5 times. The petroleum ether fraction of the extract also had a very strong contact toxicity against $5^{\text {th }}$ instar larvae of M. separata with corrected mortality of $86.8 \%$ and regression equation as a $\mathrm{Y}=2.5719+2.9107 \mathrm{X}$ and the $\mathrm{LC}_{50}$ value was $6.83 \mathrm{~g}$ extract per liter. Also, the oral toxicity showed $21.28 \%$ mortality at the concentration of 96.4 g extract per liter. ${ }^{11}$

This is the first trial for the assessment of larvicidal activity of $A$, repens against three important mosquito vectors which showed a promising result for formulating a bio-larvicide from an aggressive weed origin.

\section{CONCLUSION}

The exploration of the potentials for the renewable natural resources requires an accurate information and optimal utilization of the natural sources of herbs from different parts of Iran. Considering the job opportunity this research will guide in order to formulate a bio-larvicide for controlling the immature stages of mosquitoes. This will be resulted as an innovation and entrepreneurship, and a new way to commercialize a larvicide. Considering the fact that this plant is a dominant and unwanted weed in agriculture and due to discovering of larvicidal properties of fractions, essential oils and determining the effective compounds of these extracts is necessary and in this regard, an attempt is made to provide a stable formulation for field evaluation, especially against vectors of malaria and arboviral diseases.

\section{ACKNOWLEDGEMENT}

The authors wish to thank Mr. Naser Ghasemi, the technician of Culicidae Insectary, School of Public Health, Tehran University of Medical Sciences for his kind cooperation during the study. This study was funded and supported under code 95-02-27-32456 by Tehran University of Medical Sciences (TUMS).

\section{CONFLICT OF INTEREST}

The authors declare that they have no competing interests.

\section{ABBREVIATIONS USED}

LC: Lethal concentration; WHO: World Health Organization; ppm: Part per million; rpm: Round per min; ANOVA: One-way analysis of variance.

\section{REFERENCES}

1. World Health Organization. A global brief on vector-borne diseases. WHO. Geneva, 2014.

2. Murray NA, Quam MB, Wilder-Smith A. Epidemiology of dengue: past, present and prospects. Clin Epidemiol. 2013;5:299-309.

3. World Health Organization. Global malaria program. World malaria report 2015. Available at: apps.who.int/iris/bitstream/10665/200018/1/9789241565158_eng. pdf.

4. Oshaghi MA, et al. Anopheles stephensibiological forms, geographical distribution, and malaria transmission in malarious regions in Iran. Pakistan J Biol Sci. 2006; 9(2):294-8.

5. Maheswaran R, Ignacimuthu S. Novel biopesticide Ponneem to control human vector mosquitoes Anopheles stephensi L. and Culex quinquefasciatus Say. Environ Sci Pollut Res Int. 2015;22(17):13153-66. doi: 10.1007/s11356-015-4586-4

6. Khanavi $\mathrm{M}$, et al. Larvicidal activities of some Iranian native plants against the main malaria vector, Anopheles stephensi. Acta Medica Iranica. 2013;51(3):141-7.

7. Sedaghat MM, et al. Larvicidal activity of essential Oils of Apiaceae plants against malaria vector, Anopheles stephensi. J Arthropod-Borne Dis. $2011 ; 5(2): 51-9$

8. Sukumar K, Perich MJ, Boobar LR. Botanical derivatives in mosquito control: a review. J Am Mosq Control Assoc. 1991;7(2):210-37.

9. World Health Organization. Instruction for determining the susceptibility or resistance of mosquito larvae to insecticides. 1981. WHO/NBC/ 81.807.

10. World Health Organization. Guidelines for laboratory and field testing of mosquito larvicides, WHO/CDSMHOPES/GCDPP/2005.13.

11. Wang $X$, et al. Insecticidal activity of fraction from Acroptilon repens against larvae of Lepidoptera. Southwest China. Journal of Agricultural Sciences. 2015;28(3):1124-9 
GRAPHICAL ABSTRACT

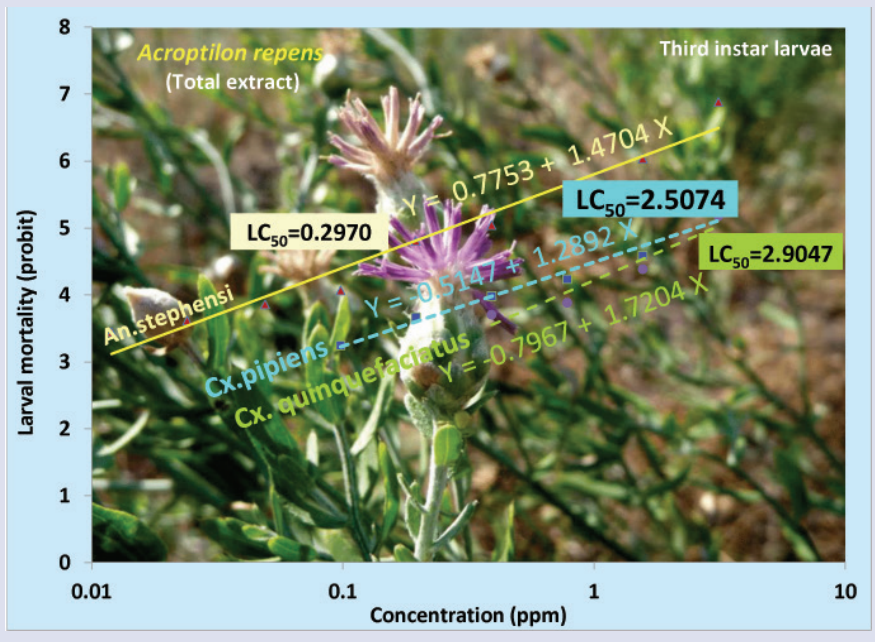

\section{SUMMARY}

- Russian Knapweed, A. repens is a dominant and unwanted weed in the ag riculture and this is the first trial for determining of larvicidal activity against three important mosquito vectors. The lethal concentrations of total extract $A$. repens ranged from 0.3 to $3.0 \mathrm{pp}$ for An. stephensi and 2.2 to $24.7 \mathrm{ppm}$ for $C x$. pipiens and $C x$. quinquefaciatus. The findings indicate the significant killing activity against mosquito larvae.

\section{ABOUT AUTHORS}

Ramesh Toolabi: MSc student in medical entomology and vector control. This paper is a part of her MSc thesis.

Mohammad Reza Abai: Academic staff who his main interest is vector control of arthropod-borne diseases with especial researches on plants having insecticidal effects.

Mohammad Mehdi Sedaghat: Associate professor and head of department of medical entomology who his main interest is vector control of arthropod-borne diseases with especial researches on plants having insecticidal effects.

Hassan Vatandoost: Professor of medical entomology and vector control who his main interest is vector control of arthropodborne diseases with especial researches on plants having insecticidal effects.

Mansooreh Shayeghi: Professor of medical entomology and vector control who her main interest is vector control of arthropodborne diseases with especial researches on plants having insecticidal effects.

Saeed Tavakoli: PhD student in pharmacology who his main interest is pharmacognosy.

Mohammad Sistanizadeh Aghdam: PhD student who his main interest is vector control.

Cite this article: Toolabi R, Abai MR, Sedaghat MM, Vatandoost H, Shayeghi M, Tavakoli S, et al. Larviciding Activity of Acroptilon repens Extract against Anopheles stephensi, Culex pipiens and Culex quinquefaciatus Under Laboratory Conditions. Pharmacog J. 2018;10(3):453-56. 